\title{
Çok Kriterli Karar Verme Analizi ve Coğrafi Bilgi Sistemi (CBS) Kullanılarak Su Kalitesinin Değerlendirilmesi
}

\author{
Mustafa Murat KAVURMACI ${ }^{1 *}$, Abdullah Korkut ÜSTÜN ${ }^{2}$ \\ ${ }^{1}$ Aksaray Üniversitesi, Jeoloji Mühendisliği Bölümü, Aksaray \\ ${ }^{2}$ Aksaray Üniversitesi, Endüstri Mühendisliği Bölümü, Aksaray
}

\begin{abstract}
ÖZET: Son yüzyılda hızla artan nüfus ve endüstrileşme nedeniyle tatlı su kaynaklarına olan talep artmaya devam etmektedir. Suya olan talep artışı, sınırlı olan temiz su kaynaklarının sürekli izlenme ve kontrol altında tutulmasını gerektirir. Bu çalışma kapsamında, İç Anadolu bölgesinde yer alan Eskil Ovasındaki yeraltı suyu kaynaklarının su kalitesi fiziksel-kimyasal veriler ve jeoistatiksel yöntemlerle incelenmiştir. Bu araştırmanın amacı, su kalitesi yönünden karışıklıkları önlemek için bir model (su kalite indeksi) geliştirmek ve yüksek su kalitesine sahip alanları belirlemektir. Bölgedeki yeraltı suyu kalitesini değerlendirebilmek amacı ile 21 farklı sulama kuyusundan su örnekleri toplanmış ve veriler Analitik Hiyerarşi Süreci (AHP) yardımıyla değerlendirilmiştir. Çalışma alanının su kalite indeksi fiziksel, kimyasal, ağır metal ve organic parametreler adı altında sınıflandırılan dört ana faktör ve onsekiz farklı alt kriter (su kalite parametresi) dikkate alınarak oluşturulmuştur.Yeraltı suyu kalite haritaları AHP modellerinden elde edilen su kalite indeksleri ve Kriging metot kullanılarak çizilmiştir. Her bir harita için yedi farklı semivariogram model test edilmiş ve en uygun model ortalama karekök hata yöntemi kullanılarak seçilmiştir. Yeraltı suyu kalite haritalarında verilen yeraltı suyu kalite indeksi çok yüksek, yüksek, orta ve düşüksu kalitesi şeklinde sınıflandırılmıştır. ESKİ değerinin 0.075 den büyük olduğu çok yüksek-yüksek su kalitesine sahip alanlar inceleme alanının güneybatısında bulunmaktadır.
\end{abstract}

Anahtar Kelimeler: Su kalitesi, su kalite indeksi, analitik hiyerarşi yöntemi, kriging metot, Eskil

\section{The Evaluation of Water Quality Using Geographical Information Systems (GIS) and Multi Attribute Decision Making}

\begin{abstract}
In the last century, the demand for freshwater resources continues to grow due to the rapidly increasing population and industrialization. This growing demand requires continuous monitoring and evaluation of the limited freshwater resources. This study investigated the spatial distribution of the groundwater quality of aquifers in the Eskil Basin in the Central Anatolian region of Turkey using physical-chemical data and geostatistical methods. The main purpose of this research was to develop a model (water quality index) to prevent any confusion in terms of water quality determination and determine optimum locations based on high water quality. For the assessment of the groundwater quality, 21 water samples were collected from different irrigation wells in the area and evaluated in terms of vulnerability using Analytic Hierarchy Process (AHP). The water quality index of the study area comprised of 18 sub-criteria (water quality parameters) classified under four main criteria of factors causing vulnerability as follows: (i) Group 1 (ii) Group 2 (iii) Group 3 and (iv) Group 4 . The groundwater quality maps were constructed using Kriging method and the water quality index obtained from the AHP model. For each map, seven different semivariogram models were tested and exponential method was determined as the best-fit model by using the root mean square standardized error values. In this study, the groundwater quality index of the zones in both maps was classified as (i) very high (ii) high (iii) moderate and (vi) low water quality. The areas that are excellent for groundwater quality were concentrated in the southwest parts of the study area where the Eskil water quality indeks (ESKI) scores were greater than 0.075 .

Key Words: water quality, water quality index, analytic hierarchy process, kriging method
\end{abstract}

\section{GİRIȘ}

Günümüzde, endüstri, tarım, turizm ve su kullanılan alanlardaki ekonomik büyüme ve hızlı nüfus artışı nedeniyle temiz ve kaliteli su kaynaklarına olan ihtiyaç hızla artmaktadır. Bununla birlikte, oldukça sınırlı olan temiz su kaynakları doğal ve antropojenik etkenler sonucunda giderek kullanılabilir özelliklerini kaybetmektedir. Düşük kalitede su kullanımı insanlarda ciddi hastalıklara ve ekosistem üzerinde kalıcı zararlara neden olabilir (Germolec ve ark., 1989;Sadat-Noori ve ark., 2014). Kurak ve yarı kurak bölgelerdeki içme, kullanma ve sulamaya elverişli kaynakların yetersizliği, bu bölgelerde daha az nitelikli kaynakların kullanımını zorunlu hale getirmektedir.

Su kalitesi, suyun kullanım amacına bağlı olarak, seçilmiş fiziksel, kimyasal ve biyolojik parametreler dikkate alınarak kullanım uygunluğunun bir ölçüsüdür (Cordy, 2001; Sun ve ark., 2016). Su kalitesi ekolojik etkileşimlerin bir sonucu olarak olumsuz yönde değişebilir (Bardalo ve ark., 2001; Diersing ve Nancy, 2009). Çözünmüş mineraller, organik madde içeriği, ağır metaller gibi parametreler su kalitesini doğrudan

*Sorumlu yazar: Kavurmac1, M. M., muratkavurmaci@yahoo.com 
etkileyen önemli faktörlerdir (Taylor, 1987). Su kalitesini kontrol eden parametreleri belirlemek ekosistemin korunması için çok önemlidir (Marjani ve Jamali, 2014).

$\mathrm{Su}$ kaynaklarının korunması ve kullanım özelliklerine uygunluk açısından kalite kaybının önlenmesi için farklı kuruluşlar tarafından birçok kıstas ve standart belirlenmiştir (WHO, 2012). Su kalite kıstasları su kaynaklarının kullanım amaçlarına göre sınıflandırılmasını sağlayacağı gibi aynı zamanda su kirliliğinin en yoğun olduğu bölgelerin saptanmasında ve alınacak tedbirlerin önceliklerinin belirlenmesi çalışmalarında da kullanılmaktadır (Chapra, 2008). Su kalite kıstaslarının sayısındaki fazlalık ve bu kıstaslar için farklı standartlar geliştirilmesi su kalitesi değerlendirme sürecini daha da karmaşık bir hale getirmektedir. Aynı su örneğini temsil eden farklı kıstaslar için çeşitli su kalite sınıflamaları ortaya ç1kabilmektedir.

Son y1llarda bu problemin çözümü için su kalitesine etki eden kıstaslar Coğrafi Bilgi Sistemi (CBS) ve Çoklu Kriterli Karar Verme (ÇKKV) analizleri gibi alternatif çözüm ve değerlendirme teknikleri yardımıyla değerlendirilmiştir. Su kalitesinin değerlendirilmesi ve mekansal dağılımlarının doğru analiz edilebilmesi CBS teknikleri ile çok daha kolay ve güvenilirdir (Zarif ve ark., 2004). Su kaynakları çalışmalarında her lokasyonda su kalite parametrelerinin belirlenmesi hem zamansal hemde maddi kayılara neden olabilmektedir. Ayrıca CBS su kalitesi için riskleri ifade etmek ve herhangi bir lokasyondaki su kalite değerinin tahmin edilebilmesi için alternatifler üretmek bakımından da etkili bir uygulamadır (Bolstad, 2005). CBS konumsal veriyi diğer veri kaynaklarıyla da birleştirebilir $(\mathrm{Fu}$ ve Sun, 2010). Bu sayede veriler organize edilerek veriler bütünleştirilebilir.

$\mathrm{Bu}$ makalede İç Anadolubölgesinde Aksaray il sınırları içerisinde Tuz Gölü'nün güney kıyı çizgisi boyunca yer alanEskil ve çevresindeki tatlı su akiferlerininsu kalitesi açısından mevcut durumları, su kalitesinin mekansal dağılımları ve Tuz Gölü ile olan etkileşim potansiyelleri jeoistatiksel yöntemler ve CBS teknikleri kullanılarak araştırılmıştır. İnceleme alanında son yıllarda yeraltı suyunun aşırı kullanımı ve yüzeysel su kaynaklarının yokluğu yüksek su kalitesine sahip olan yeraltı suyuna olan talebi daha da artırmıştır. Bu makalenin ana amacı, su kalite verilerini tek bir su kalite indeksi altında birleştirmek ve yüksek su kalitesine sahip alanları belirlemektir.

$\mathrm{Bu}$ çalışmanın sonuçları, tarımsal uygulamalarda, şehir ve bölge planlarının oluşturulmasında, ekosistem planlarının hazırlanmasında can ve mal güvenliğini artırmak için kullanılabilir. Ayrıca bu çalışma bölgede su kalitesinin belirlenmesi konularında araştırma yapacak sonraki araştırmacılara da yol gösterici olacaktır.

\section{MATERYAL ve METOT}

\section{Örnekleme ve Analizler}

Araştırma kapsamında Mayıs 2015 ve Eylül 2015 tarihlerinde 21 sulama amaçlı açılan kuyudan su örnekleri toplanmış ve bu örnekler üzerinde fiziksel ve kimyasal su kalite analizleri gerçekleştirilmiştir. Su örnekleri asitli ve asitsiz olarak çift kapaklı 1 litrelik polietilen şişelere alınmıştır. Örnekleme dönemlerine ait su örneklerinin analizleri Aksaray Üniversitesi Çevre Mühendisliği Bölümü $\mathrm{Su}$ Kimyası Laboratuvarında yapılmıştır.

Örnekleme dönemlerinde yeraltı su seviyesi, $\mathrm{pH}$, sıcaklık, elektriksel iletkenlik (EC), toplam çözünmüş katı madde (TDS) ve tuzluluk gibi fiziksel parametreler yerinde ölçülmüştür. Fiziksel parametre değerlerinin ölçümünde WTW-LT 330 marka portatif kondüktivite metre (SCT), Orion marka "pH metre" ve YSI- 055 "oksijenmetre" kullanılmıştır. Suların sülfat, fosfat, nitrat, nitrit, florür, klorür, bromür gibi anyon değerleri Dionex Ics-1000 ion chromatography tipi cihaz ile ölçülmüştür. Suların kimyasal katyon ve ağır metal analizlerinde ise Perkinelmer Optima 2100 DV ICPOES- USA cihazı kullanılarak ölçülmüştür.

$\mathrm{Su}$ kimyası analizlerinden elde edilen veriler uygun veri tabanı formatında düzenlendikten sonra jeoistatiksel yöntemler kullanılarak değerlendirilmiş ve CBS uygulamaları yardımıyla inceleme alanının değişik tip ve ölçekte su kalite haritaları üretilmiştir.

\section{Çalışma Alanının Tanıtılması}

İnceleme alanı, Türkiye'de İç Anadolu Bölgesi'nde $33014^{\prime}$ ve $33035^{\prime}$ doğu boylamları ile $38012^{\prime}$ ve 380 26' kuzey enlemleri arasında yer alır (Şekil 1). İnceleme alanının ortalama denizden yüksekliği 960 m. kapladığı alan ise $800 \mathrm{~km}^{2}$ dir. Bölgenin ortalama yıllık sıcaklığ $12.4{ }^{\circ} \mathrm{C}$, ortalama yıllık yağış miktarı ise $360 \mathrm{~mm}$.'dir. İnceleme alanı düz bir topoğrafyaya sahiptir. İnceleme alanı içerisinde episodik akarsuların dışında önemli bir akarsu ağı bulunmaz. Bölgenin en önemli su yapısı $1665 \mathrm{~km}^{2}$ 'lik ortalama yüzey alanına sahip Türkiye'nin ikinci büyük ve en sığ gölü olan Tuz Gölü'dür. Tuz Gölü kapalı bir havza gölüdür. Yağış alanı 11900 km² dir. Göl çok geniş bir yağış alanına sahip olmasına rağmen genelde $\mathrm{NaCl}^{\prime}$ ce zengin yeraltı suları tarafindan beslenir (Kavurmac1, 2013). 




Şekil 1. Çalışma alanının genel görünüşü ve örnekleme noktalarının dağılımı

Tuz Gölü'nün güneyinde Eskil kasabası bulunur. Eskil ve çevresi bölgenin en önemli tarım arazilerinden birisidir. Bölgede su ile tarım yapıldığı için yeraltı suları oldukça yaygın olarak kullanılır. İnceleme alanında içme ve sulama amacı ile açılmış 500 den fazla su kuyusu vardır. Bu kuyuların derinlikleri 40 ile 150 metre debileri ise 2 ile $10 \mathrm{Litre} /$ saniye arasında değişir. Yeraltı sularının tuzlanması bölgedeki en önemli sorunlardan birisidir.

\section{Jeolojik ve Hidrojeolojik Sistem}

Çalışma alanının temelinde Orta Anadolu Kristalen Kompleksi olarak tanımlanan kaya birimi yeralır.Bu kompleks düzenli bir istif sunan Orta Anadolu Metamorfitleri, Orta Anadolu Ofiyolitleri ile bu birimleri sicak dokanakla kesen Orta Anadolu Granitoyitleri'nden meydana gelen kristalen kayalarla temsil edilir (Göncüoğlu ve ark.,1996). Tuz Gölü Havzası Geç Kretase - Oligosen zaman aralığında gelişmiştir. Sübsidans Geç Kretase - Orta Eosen süresince meydana gelmiş ve bunu Geç - Orta Eosen'den başlayan ve Oligosen sonlarına kadar devam eden regresyon takip etmiştir (Arıkan, 1975). Tuz Gölü Havzası Geç Kretase'den başlayıp Orta Eosen sonuna kadar denizel ve Geç Eosen - Kuvaterner zaman aralığında karasal nitelikli sedimanter birimlerle doldurulmuștur (Arıkan, 1975; Çemen ve ark., 1999; Dirik ve Erol, 2000). Sedimanter istifin kompozit kalınlığı bölgede yaklaşık 2500 metre civarındadır (Göncüoğlu ve ark., 1996). Bölgedeki en önemli yapısal unsur Sultanhanı Fay Zonu'dur. Bu fay zonu KD GBgidişli birbirlerine paralel doğrultu atımlı fay sistemleri ve ana fayı farklı açılarla kesen KB - GD gidişli düşey bileşenli fay sistemlerinden oluşur.

İnceleme alanında akifer oluşturan en önemli birim Tersiyer yaşlı sedimanter istifin kireçtaşı, çakıltaşı ve kumtaşı seviyeleridir. Kireçtaşları içerisinde düşey yönde gelişen çatlaklı, kırıklı ve karstik boşluklu kısımlar hidrojeolojik açıdan geçirimlidir. Geçirimli birimler inceleme alanındaki sığ dolaşımlı düşük debili soğuk su kaynakları için önemli bir akifer özelliğindedir. Küçük debili soğuk su kaynaklarının çoğu fay hatlarına bağlı olarak gelişen kırık sistemlerinden veya bağlantısız akiferlerden oluşmaktadır. Tuz Gölü'nün güneyinde yer alan Kuvaterner yaşlı alüvyon genelde kohezyon değeri yüksek ince taneli birimlerden oluştuğundan dolayı orta verimli akifer olarak sınıflandırılmıştır.

\section{Su Kalitesi Değerlendirme İndeksinin Kurulması}

$\mathrm{Bu}$ çalışmanın amaçlarından birisi de Eskil bölgesinin su kalitesini değerlendirebilmek için basit ve uygun bir su kalite indeksi geliştirmektir.Su kalite indeksi herhangi bir su kütlesine ait çok fazla sayıdaki su kalite kıstaslarını tek bir sayı altında birleştiren boyutsuz bir sayıdır (Miller ve ark., 1986) ve ilk olarak Horton (1965) tarafindan geliştirilmiştir. Son yıllarda, su kalitesi belirleme çalışmalarında birçok araştırmacı tarafindan çoklu karar verme analiz teknikleri uygulanarak yaygın olarak kullanılmıştır (Liou ve ark., 2004; Nasiri ve ark., 2007; Boyacioğlu, 2007; Ramakrishnaiah ve ark., 2009; Banerjee ve Srivastava, 2009; Sener ve Davraz, 2013; Selvam ve ark., 2014; Abtahi ve ark., 2015). Su kalitesini değerlendirmek için 
farklı araştırmacılar tarafından geliştirilen su kalite indeksleri olmasına rağmen, her bölgenin jeolojik, hidrojeolojik ve ekolojik özellikleri birbirinden farklıdır (Hem, 1985).

$\mathrm{Bu}$ çalışma kapsamında su kalite indeksinin geliştirilmesi için AHP metotu kullanılmıştır (Şekil 2). AHP en çok kullanılan MCDM tekniklerinden biridir. Metot Saaty (2005) tarafindan geliştirilmiştir. AHP çeşitli ölçütleri kullanarak, karar alternatiflerini kendi içerisinde kıyaslayarak sıralar ve ilgili karar alternatiflerinden en uygun olanını mevcut koşulları da dikkate alarak belirler. Metotun temeli ölçütler, alt ölçütler ve karar alternatifleri arasında ikili karşılaştırmalara dayanır. Karşılaştırmalar yapılırken konuyla ilgili farklı uzmanların sübjektif objektif değerlendirmelerinden karar sürecinde yararlanılır. $\mathrm{Bu}$ değerlendirmeler belli oranda tutarsızlığın ikili karşılaştırmalarda yer almasını sağlar. İlgili veri grubunun çalışmada kullanılabilmesi için tutarsızlık oranının 0.1'den az olması gerekir (Saaty, 2005; Yazgan ve Üstün, 2011).

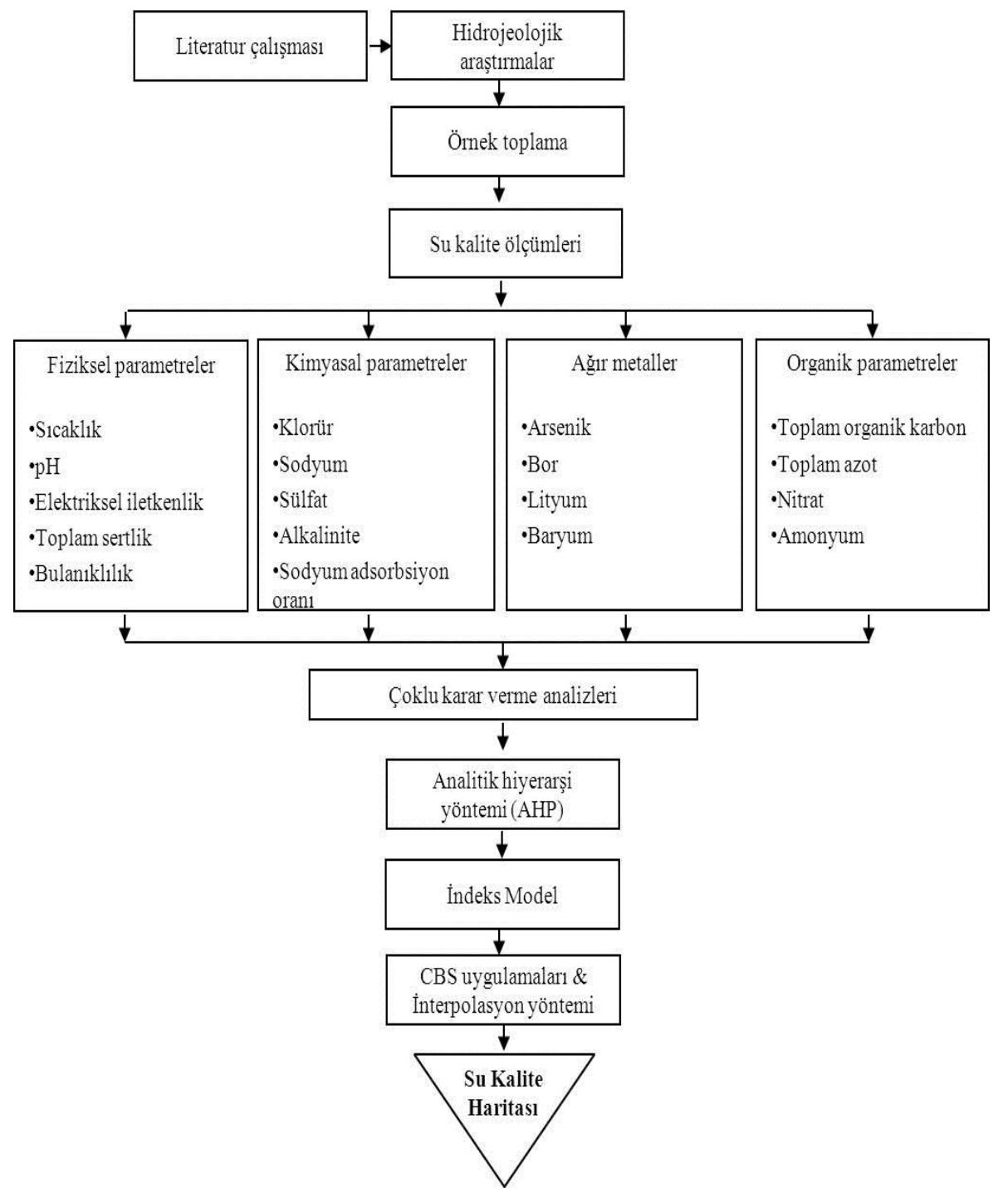

Şekil 2. Çalışmanın metodolojisi

Bu çalışma kapsamında oluşturulan su kalite indeksi üç aşamalı bir hiyerarşiden oluşur. Hiyerarşinin ilk aşaması çalışmanın amacı, ikinci aşaması ölçütler ve bu ölçütlerin alt ölçütleri, son aşaması ise karar alternatiflerinden oluşur. Ölçütler ve alt ölçütlerin belirlenmesi ayrıca karşılaştırma matrislerinin oluşturulma aşamalarında Aksaray Üniversitesi'nde görev yapan ve su kalitesi üzerine bilimsel çalışmaları bulunan 12 farklı uzmandan alınan görüşlerin geometrik ortalaması kullanılmıştır. 
Su kalite indeksinin oluşturulması için 4 ana ölçüt grubu altında toplam 18 alt ölçüt belirlenmiştir (Çizelge 1). Bu ölçütler: (i) fiziksel parametreler ( $\mathrm{pH}$, elektriksel iletkenlik, sertlik, bulanıklık ve sıcaklık), (ii) kimyasal parametreler (klorür, sodyum, sülfat, alkalinite ve sodium adsorbsiyon oranı), (iii) ağır metallar (arsenik, bor, lityum ve baryum) ve (iv) organic parametreler (toplam organik karbon, toplam azot, amonyum ve nitrat) olarak çalışma alanının özelliklerinin yanısıra TS266 ve WHO (2012) içme suyu standartları dikkate alınarak belirlenmiştir (Çizelge 2).

Çizelge 1. Modelleme için kullanılan verilerin istatiksel özeti

\begin{tabular}{|c|c|c|c|c|c|c|c|c|c|c|}
\hline \multirow[b]{2}{*}{ Parametre } & \multirow[b]{2}{*}{$\mathrm{n}$} & \multirow[b]{2}{*}{ Birim } & \multicolumn{4}{|c|}{ Mayıs 2015} & \multicolumn{4}{|c|}{ Eylül 2015} \\
\hline & & & Min. & Max. & Ort. & Sp & Min. & Max. & Ort. & Sp \\
\hline Sicakl & 21 & $\left({ }^{0} \mathrm{C}\right)$ & 10.53 & 21.47 & 15.7 & 2.86 & 12.7 & 20.0 & 15.9 & 1.9 \\
\hline pH & 21 & 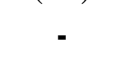 & 6.62 & 8.21 & 7.4 & 0.48 & 6.4 & 8.3 & 7.5 & 0.5 \\
\hline Elektriksel iletkenlik & 21 & $(\mu \mathrm{S} / \mathrm{cm})$ & 337.46 & 2530.98 & 1068.1 & 514.12 & 361.1 & 2708.1 & 1152.4 & 545.3 \\
\hline Toplam çözünmü katı madde & 21 & $(\mathrm{mg} / \mathrm{L})$ & 208.20 & 1969.50 & 851.0 & 419.18 & 234.6 & 2238.3 & 915.9 & 468.0 \\
\hline Bulanıkl & 21 & (NTU) & 0.19 & 9.70 & 3.8 & 3.07 & 0.6 & 10.2 & 4.1 & 2.9 \\
\hline Klorür & 21 & $(\mathrm{mg} / \mathrm{L})$ & 12.69 & 329.72 & 123.8 & 87.69 & 16.8 & 441.0 & 146.0 & 110.3 \\
\hline Alkalinite & 21 & $(\mathrm{mg} / \mathrm{L})$ & 180.29 & 1539.30 & 492.8 & 306.02 & 200.1 & 1462.3 & 511.1 & 284.9 \\
\hline Toplam & 21 & $(\mathrm{mg} / \mathrm{L})$ & 165.00 & 877.00 & 488.9 & 180.14 & 184.1 & 1004.9 & 531.3 & 199.9 \\
\hline Bikar & 21 & $(\mathrm{mg} / \mathrm{L})$ & 219.95 & 1877.95 & 601.2 & 373.34 & 244.1 & 1784.1 & 623.6 & 347.6 \\
\hline Sülfat & 21 & $(\mathrm{mg} / \mathrm{L})$ & 13.56 & 429.71 & 104.4 & 92.88 & 13.8 & 446.9 & 112.7 & 100.7 \\
\hline Nitrat & 21 & $(\mathrm{mg} / \mathrm{L})$ & 0.79 & 18.55 & 6.7 & 5.65 & 3.2 & 26.1 & 8.8 & 5.8 \\
\hline Amonyum & 21 & $(\mathrm{mg} / \mathrm{L})$ & 0.01 & 0.19 & 0.1 & 0.05 & 0.0 & 0.2 & 0.1 & 0.0 \\
\hline Toplam & 21 & $(\mathrm{mg} / \mathrm{L})$ & 1.41 & 9.58 & 4.0 & 1.75 & 1.6 & 8.4 & 3.8 & 1.6 \\
\hline Topla & 21 & $(\mathrm{mg} / \mathrm{L})$ & 0.73 & 17.18 & 6.1 & 4.79 & 1.1 & 16.5 & 6.1 & 4.6 \\
\hline Kalsiyum & 21 & $\mathrm{mg} / \mathrm{L}$ & 47.53 & 178.74 & 119.0 & 41.03 & 53.0 & 212.4 & 125.1 & 45.2 \\
\hline Sodyum & 21 & $\mathrm{mg} / \mathrm{L}$ & 22.77 & 661.72 & 135.6 & 152.50 & 25.5 & 761.0 & 151.9 & 172.5 \\
\hline Magnez & 21 & $\mathrm{mg} / \mathrm{L}$ & 9.42 & 108.98 & 46.7 & 25.73 & 12.5 & 125.3 & 53.3 & 29.7 \\
\hline Potasyum & 21 & $\mathrm{mg} / \mathrm{L}$ & 0.68 & 14.78 & 5.6 & 3.43 & 0.9 & 13.7 & 5.8 & 3.2 \\
\hline Arsen & 21 & $\mathrm{mg} / \mathrm{L}$ & 0.01 & 0.21 & 0.04 & 0.05 & 0.01 & 0.18 & 0.03 & 0.04 \\
\hline Bor & 21 & $\mathrm{mg} / \mathrm{L}$ & 0.18 & 3.21 & 0.92 & 0.79 & 0.19 & 3.64 & 0.82 & 0.80 \\
\hline Baryl & 21 & $\mathrm{mg} / \mathrm{L}$ & 0.01 & 0.42 & 0.09 & 0.08 & 0.00 & 0.37 & 0.07 & 0.07 \\
\hline Lityum & 21 & $\mathrm{mg} / \mathrm{L}$ & 0.01 & 0.38 & 0.11 & 0.09 & 0.00 & 0.44 & 0.10 & 0.10 \\
\hline Sodyum ads orbsiyon oranı & 21 & - & 0.64 & 9.72 & 2.49 & 2.32 & 0.7 & 10.4 & 2.6 & 2.4 \\
\hline
\end{tabular}

n: örnek sayıs1, Min: minumum, Max: maksimum, Ort: ortalama, sp: standart sapma

Sonraki aşamada $n$ ölçütün olduğu varsayıldığında $n$ $\mathrm{x} \mathrm{n}$ boyutlu köşegen elemanlarının 1 değerini aldığı ikili karșlaştırma matrisleri oluşturulmuştur. Çünkü ilgili ölçüt kendisi ile kıyaslanmıştır ve eşit önemde anlamına gelen "1" değerini almıştır. Köşegenin altıda kalan matris bileşenleri için ise $a j i=1 / a_{i j}$ formülü kullanılmıştır. $\mathrm{Bu}$ ölçütlerin kendi aralarında karşıllaştırılması ve alternatiflerin herhangi bir ölçüte göre kıyaslanmasında Çizelge3'de verilen Saaty (2008) tarafından önerilen skala kullanılmıştır. İkili karşılaştırmalar yapilırken karar alternatifleri, ölçüt ve alt ölçütler kendi aralarında bu skala kullanılarak değerlendirilmiștir. Karşılaştırma matrisleri yardımıyla hiyerarşi içerisinde yer alan her ölçütün öncelik ve ağırlık vektörleri belirlenmiş ve Eskil Su Kalite İndeksi (ESKI) geliştirilmiştir (Çizelge4).Uygulamanın son aşamasında yapılan ikili karşılaştırmaların tutarsızlık değeri 0,008 olarak hesaplanmıştır. Kurulan matrisler ve yapılan karşılaştırmalar tutarlıdır ve bu karşılaştırmalar değerlendirme sürecinde kullanılabilirler. 
Çizelge 2. AHP için verilerin karşılaştırma aralıkları

\begin{tabular}{lcccc} 
Parametre & Çok iyi & İyi & Kötü & Çok kötü \\
\hline T & $<15$ & $15-25$ & $>25$ & $>30$ \\
pH & $6.5-7.5$ & $7.5-8.5$ & $>8.5$ & $<6.5$ \\
EC & $<250$ & $250-1000$ & $1000-2250$ & $>2250$ \\
T. Sertlik & $<150$ & $150-500$ & $500-1000$ & $>1000$ \\
Bulanıklık & $<5$ & $5-25$ & $25-50$ & $>50$ \\
Klorür & $<25$ & $25-200$ & $200-400$ & $>400$ \\
Sodyum & $<125$ & $125-250$ & $250-1000$ & $>1000$ \\
Sülfat & $<200$ & $200-400$ & $400-1000$ & $>1000$ \\
Alkalinite & $<250$ & $250-500$ & $500-1000$ & $>1000$ \\
SAR & $<10$ & $10-18$ & $18-26$ & $>26$ \\
As & $<0.01$ & $0.01-0.05$ & $0.05-0.1$ & $>0.1$ \\
B & $<0.1$ & $0.1-0.5$ & $0.5-1$ & $>1$ \\
Li & $<0.01$ & $0.01-0.05$ & $0.05-0.1$ & $>0.1$ \\
Ba & $<0.5$ & $0.5-1$ & $1-2$ & $>2$ \\
TOK & $<5$ & $5-8$ & $8-12$ & $>12$ \\
TA(TN) & $<0.5$ & $0.5-2$ & $2-5$ & $>5$ \\
Nitrat-N & $<5$ & $5-20$ & $20-50$ & $>50$ \\
Amonyum-N & $<0.02$ & $0.02-0.1$ & $0.1-1$ & $>1$ \\
\hline
\end{tabular}

Çizelge 3. AHP karşılaştırma sürecinde kullanılan önem değerleri (Saaty, 2008)

\begin{tabular}{|c|c|}
\hline $\begin{array}{c}\text { Önem } \\
\text { değerleri }\end{array}$ & Tanımları \\
\hline 1 & Karş 1laş tırılan her iki ölçütte eşit öneme sahiptir \\
\hline 3 & 1. ölçütün 2. ölçütten daha önemli olmas 1 durumu \\
\hline 5 & 1. ölçütün 2. ölçütten çok önemli olması durumu \\
\hline 7 & $\begin{array}{l}\text { 1. ölçütün 2. ölçüte nazaran çok güçlü bir öneme sahip olmas } 1 \\
\text { durumu }\end{array}$ \\
\hline 9 & $\begin{array}{l}\text { 1. ölçütün 2. ölçüte nazaran mutlak üstün bir öneme sahip olmas } 1 \\
\text { durumu }\end{array}$ \\
\hline
\end{tabular}


Çizelge 4. Her bir kuyu için AHP kullanılarak üretilen Eskil su kalite indeks değerleri

\begin{tabular}{ccc}
\hline Örnek & ESKi-Mayıs & ESKí-Eylül \\
\hline Sk1 & 0.02527 & 0.02152 \\
Sk2 & 0.02522 & 0.02448 \\
Sk3 & 0.09138 & 0.08929 \\
Sk4 & 0.03826 & 0.03464 \\
Sk5 & 0.04490 & 0.04235 \\
Sk6 & 0.05838 & 0.05895 \\
Sk7 & 0.04212 & 0.04114 \\
Sk8 & 0.08126 & 0.08407 \\
Sk9 & 0.04190 & 0.04333 \\
Sk10 & 0.08149 & 0.08831 \\
Sk11 & 0.02058 & 0.02079 \\
Sk12 & 0.02368 & 0.02595 \\
Sk13 & 0.05373 & 0.05226 \\
Sk14 & 0.04599 & 0.04645 \\
Sk15 & 0.06237 & 0.06499 \\
Sk16 & 0.04172 & 0.04014 \\
Sk17 & 0.04119 & 0.04200 \\
Sk18 & 0.05915 & 0.06275 \\
Sk19 & 0.03815 & 0.03253 \\
Sk20 & 0.04231 & 0.04273 \\
Sk21 & 0.04142 & 0.04225 \\
\hline EK1 Eski &
\end{tabular}

\section{BULGULAR ve TARTIŞMA}

\section{Hidrojeokimyasal Değerlendirme}

Örnekleme noktalarından Mayıs 2015 ve Eylül 2015 tarihlerinde mevsimsel değişimler göz önüne alınarak örnekleme ve kimyasal analiz çalışmaları yapılmıştır. Söz konusu sular için Mayıs örnekleme dönemine ait bazı fiziksel ve kimyasal parametrelerin değerleri; sicaklık (T) $10.5{ }^{\circ} \mathrm{C}-21.4{ }^{\circ} \mathrm{C}$, pH 6.6 - 8.2, elektriksel iletkenlik (EC) $337.4-2530.9 \mu \mathrm{S} / \mathrm{cm}$, toplam çözünmüş katı madde (TDS) 208.2 - 1969.5 mg/L arasında değişmiştir (Çizelge5a,b).İnceleme alanında suların fiziksel ölçümleri mevsimsel değişmelere bağlı olarak çok azdeğişim göstermektedir. Fiziksel parametre değerleri genel olarak yağış miktarının artması bağlı olarak Mayıs örnekleme döneminde düşüş eğilimi gösterir.Ancak örnekleme dönemleri boyunca homojen bir dağılım veya sistematik bir artış belirlenememiştir.Bunun nedeni suların diğer sularla karışımları veya sulama amaçlı kullanımları olabilir.Sular $\mathrm{pH}$ değerlerine göre hafif çözücü hafif kabuklaştırıcı bazik özelliğe sahiptir.EC değerlerinin tamamı Dünya Sağlık Örgütü (WHO, 2012) tarafından belirlenen içme suyu standartlarının üzerindedir.EC değerlerinin farklı değerler almasının nedeni suların su kayaç temas sürelerinin farklı olması veya suların izlediği yol boyunca çözünürlükleri ve iyon içerikleri farklı kayaçlarla temas etmesi olabilir.

Hidrokimyasal açıdan sular $\mathrm{CaHCO}_{3}, \mathrm{NaHCO}_{3}$ ve $\mathrm{MgHCO}_{3}$ su fasiyesi özelliğindedir (Şekil 3).Söz konusu suların iyon bolluk dizilimleri genel olarak $\mathrm{Ca}^{+2}>\left(\mathrm{Na}^{+}\right.$ $\left.+\mathrm{K}^{+}\right)>\mathrm{Mg}^{+2} / \mathrm{HCO}_{3}^{-}>\mathrm{Cl}^{-}>\mathrm{SO}_{4}^{-2}$, şeklinde gelişmiştir.Bu sular karbonat alkalinitesi karbonat olmayan alkaliniteden fazla karbonat sertliği yüksek $\mathrm{CaHCO}_{3}$ tipli sulardır.Bu suların $\mathrm{CaHCO}_{3}$ fasiyesi göstermeleri suların karbonat kökenli bir akiferden beslendiklerini göstermektedir.Sk1, Sk2, Sk4, Sk11 ve Sk 12 numaralı örnekler ise $\left(\mathrm{Na}^{+}+\mathrm{K}^{+}\right)>\mathrm{Ca}^{+2}>\mathrm{Mg}^{+2}$ $/ \mathrm{HCO}_{3}{ }^{-}>\mathrm{Cl}^{-}>\mathrm{SO}_{4}{ }^{-2}$ iyon dizilimine sahiptir.Bu sular bölgede karışım sularını temsil ederler.İyon bolluk dizilimleri bütün örnekleme dönemleri boyunca aynı kalmıştır.Tuz Gölü'nden uzaklaştıkça su kimyası fasiyesleri sirasıyla genel olarak $\mathrm{NaHCO}_{3}-\mathrm{CaHCO}_{3}$ şeklinde değişir.Yağışılı dönemde $\mathrm{Ca}^{+2}$ ve $\mathrm{HCO}_{3}{ }^{-}$iyonları daha fazla çözünmüş ve baskın konuma geçmişlerdir. 
Çizelge 5a. İnceleme alanına ait su örneklerininfiziksel ve kimyasal analiz sonuçları (Mayıs 2015)

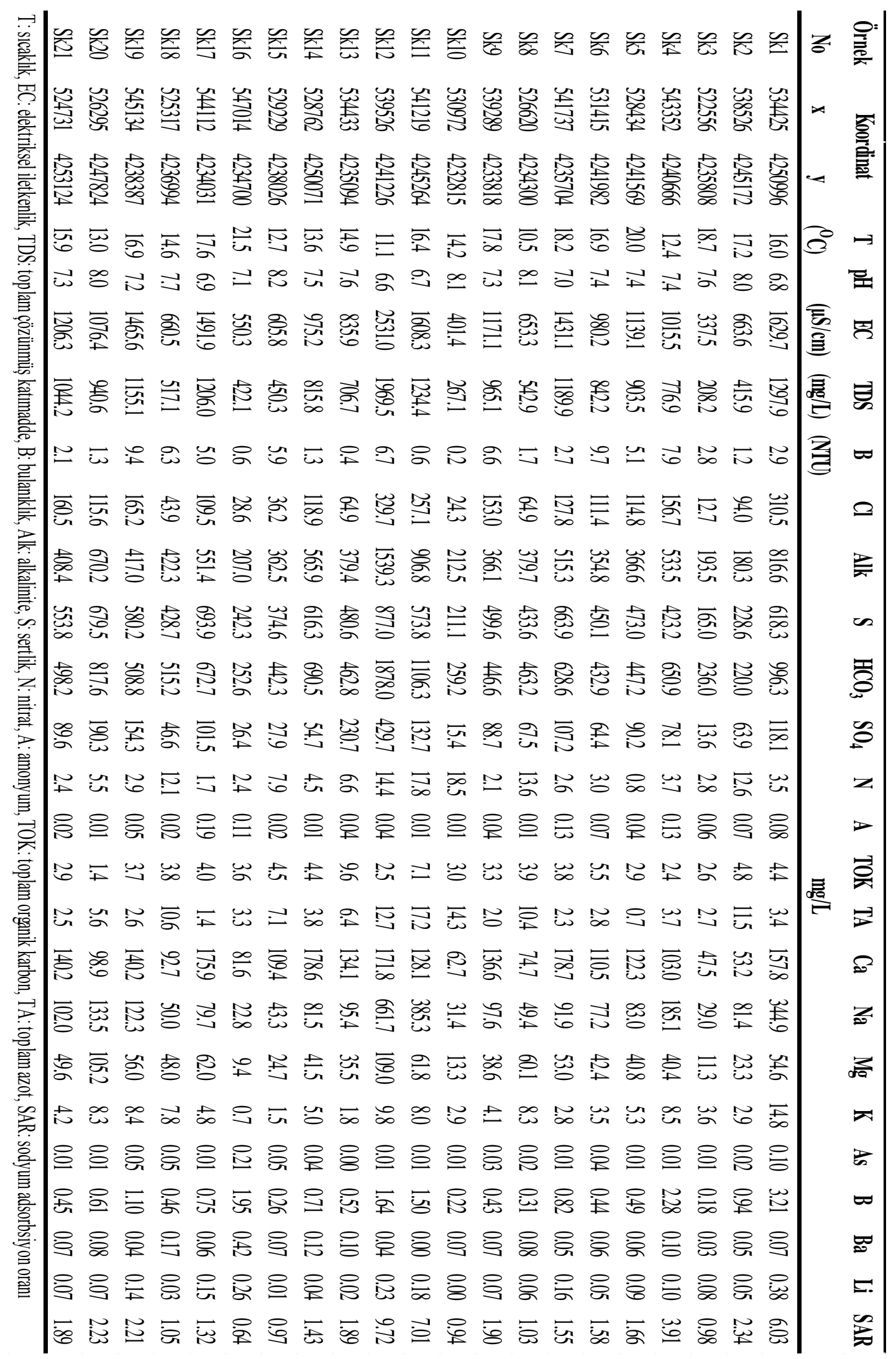


Çizelge 5b. İnceleme alanına ait su örneklerininfiziksel ve kimyasal analiz sonuçları (Eylül 2015)

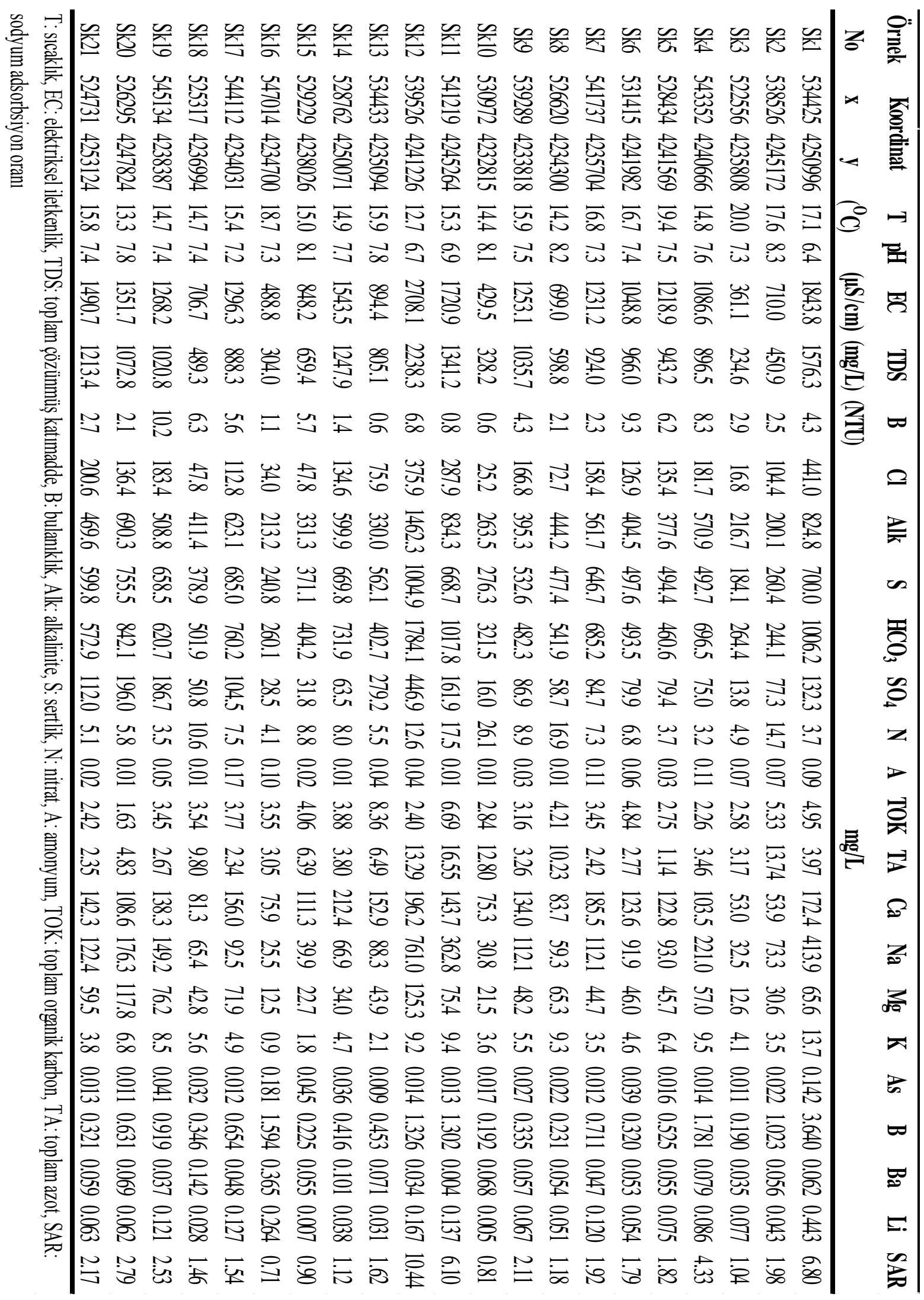




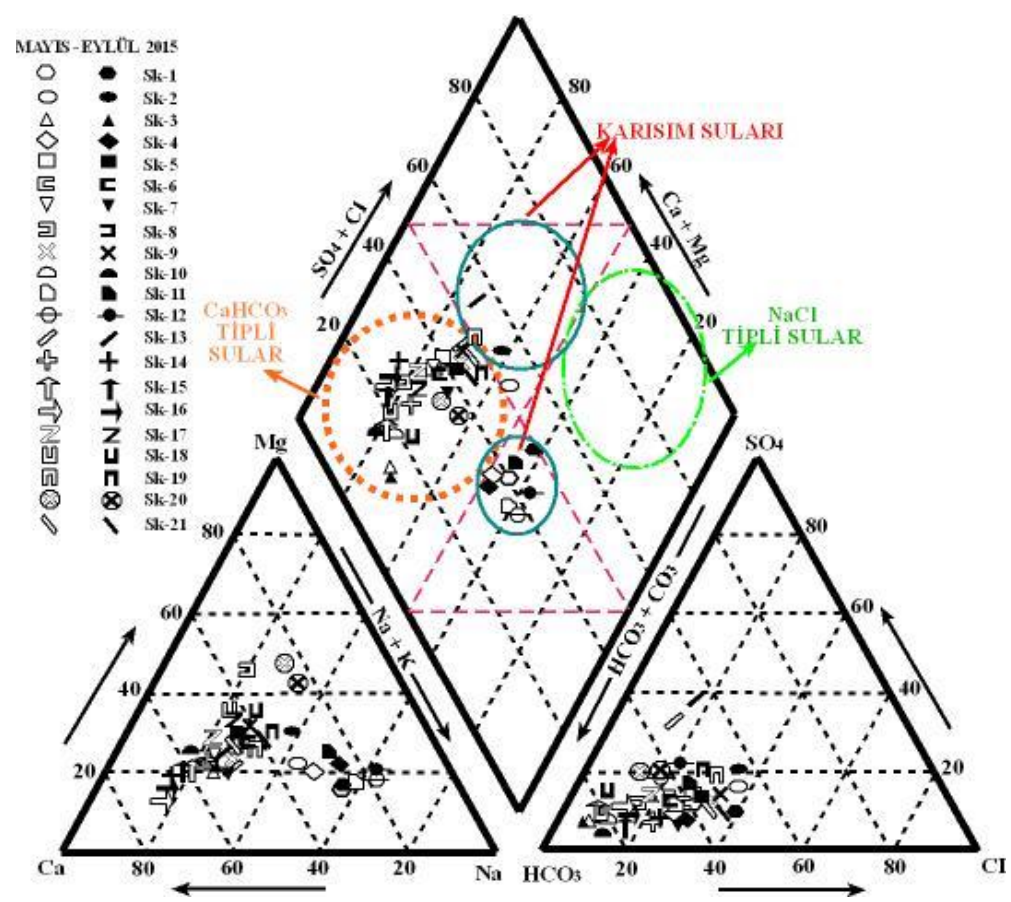

Şekil 3. İnceleme alanındaki sulara ait üçgen diyagram

\section{ESKİ kullanılarak yeraltı suyu kalite dağılımının belirlenmesi \\ Calışma kapsamında ESKİ verileri ArcGIS yazılımı} ESDA (explatory spatial data analysis) araçlar kullanılarak jeoistatiksel açıdan değerlendirilmiş ve su kalite haritalarının oluşturulmasında kriging interpolasyon yöntemi tercih edilmiştir. Kriging, verilerin birbirine bağımlı olması ilkesinden yola çıkarak ölçülmüş değerlerden ölçülmemiş noktaların tahmin edilebilmesi için kullanılan bir interpolasyon tekniğidir (Aldworth, 1998). Veriler arasındaki mesafenin fonksiyonuna bağlı olarak örneklenmemiş bir noktadaki değeri hesaplamak aşağıda verilen eşitlikle mümkündür;

$$
\mathrm{Z}\left(\mathrm{x}_{\mathrm{o}}\right)=\sum_{\mathrm{i}=1}^{\mathrm{N}} \lambda_{\mathrm{i}} \mathrm{Z}\left(\mathrm{x}_{\mathrm{i}}\right)
$$

Eşitlikle $\mathrm{Z}\left(\mathrm{x}_{\mathrm{i}}\right)$ : i lokasyonunda ölçülen değer, $\lambda_{\mathrm{i}}: \mathrm{i}$ lokasyonunda ölçülen değer için ağırlık katsayısı, $X_{0}$ : o lokasyonundaki tahmin edilecek değer, $\mathrm{N}$ : ölçülmüş değerler sayısıdır.

$\mathrm{Bu}$ yöntem mekansal değişimleri açıklamak için variogramlar kullanır. En büyük özelliği ise, su kalitesini değerlendirirken, kalite sürekliliği, etki mesafesi ve yönü gibi değişkenleri bir fonksiyon şeklinde ifade etmesidir. Diğer bir deyişle variogram $\gamma(\mathrm{h})$, inceleme alanında su kalitesinin uzaklıkla nasıl değiştiğini gösteren bir eğridir ve aşağıdaki eşitlik ile gösterilir (Oliver, 1990);

$$
\gamma(\mathrm{h})=\frac{1}{2 \mathrm{n}} \sum_{\mathrm{i}=1}^{\mathrm{n}}\left[\mathrm{Z}\left(\mathrm{x}_{\mathrm{i}}\right)-\mathrm{Z}\left(\mathrm{x}_{\mathrm{i}}+\mathrm{h}\right)\right]^{2}
$$

$\gamma(\mathrm{h})$ : semi-variogram değeri, h: noktalar aras1 uzaklık (lag mesafesi), $\mathrm{z}\left(\mathrm{x}_{\mathrm{i}}\right)$ ve $\mathrm{z}\left(\mathrm{x}_{\mathrm{i}}+\mathrm{h}\right)$ : $\mathrm{x}$ noktasındaki değer ve bu noktadan $h$ mesafedeki değer.

Bölgesel değişken, su kalitesi açısından yoğun ve düşük bölgeler şeklinde geçişli bir yapı sergiliyorsa, variogram belirli bir uzaklıktan sonra artışını durdurur ve belirli bir değerde sabit kalır. Bu değere Tepe değeri (C), variogramın bu değeri aldığı uzaklığa da yapısal uzaklık (a) denir. Bu uzaklık kovaryansın sıfır olduğu ve fiziksel olarak bir örneğin etki zonu anlamına gelir. Etki zonu dişında örneklerin birbiriyle korelasyonu yoktur ve birbirlerinden bağımsızdırlar (Tercan ve Saraç, 1998). Variogram her zaman pozitif değerler aldığından seçilecek fonksiyonun da pozitif tanımlı bir fonksiyon olması gerekmektedir (Clark, 1979).

$\mathrm{Bu}$ çalışmada her bir örnekleme noktası için ESKİ değerleri kullanılarak ayrı ayrı deneysel variogramlar oluşturulmuştur. Daha sonra deneysel variogramlara uygun teorik modeller belirlenmiştir. Her bir su kalite haritası için tepe değerli modeller (küresel model, exponential (üssel) model, gauss modeli ve linear modeli) test edilmiştir. Exponential (üssel) model hataların ortalama karekökü değerine göre su kalite haritası için en uygun model olarak belirlenmiștir. Exponential (üssel) model kullanılarak kriging interpolasyon yöntemi ile inceleme alanı için $3 \times 3$ metre aralıklarla noktasal ESKİ değeri tahminleri yapılmış ve farklı örnekleme dönemlerine göre bölgenin su kalite dağılım haritaları hazırlanmıştır (Şekil 4). Dağılım haritalarının $\mathrm{R}^{2}$ ve ortalama karesel hata değerleri Mayıs ve Eylül ayları için sırasıyla 0.96-0.98, 0.97-1.03'dur. 
Yapılan değerlendirmeler sonucunda su kalite haritaları çok yüksek kalite, yüksek kalite, orta kalite ve düşük

Çizelge 6. ESKİ değerlendirme kriterlerinin açıklanması

\begin{tabular}{|c|c|c|}
\hline ESKI & Tanımlama & Açıklama \\
\hline $0.1-0.075$ & Çok yüksek su kalitesi & İçme ve kullanma suyu olarak kullanmak güvenlidir \\
\hline $0.075-0.050$ & Yüksek su kalitesi & $\begin{array}{l}\text { İçme ve kullanma suyu olarak kullanmak genellikle } \\
\text { güvenlidir }\end{array}$ \\
\hline $0.050-0.025$ & Orta su kalitesi & $\begin{array}{l}\text { İçme suyu kullanımı için sağlığı tehdit eden bazı } \\
\text { unsurlar içerebilir fakat kullanma suyu olarak } \\
\text { kullanılabilir }\end{array}$ \\
\hline $0-0.025$ & Düşük su kalitesi & İçme suyu olarak kullanılamaz \\
\hline
\end{tabular}



Şekil 4. İnceleme alanındaki su kalitesinin mekânsal ve zamansal dağılımı 
Çok yüksek su kalitesi içeren alanlar inceleme alanının güneybatı bölgelerinde yoğunlaşmıştır. $\mathrm{Bu}$ alanlar inceleme alanının yaklaşık \% 29.3 temsil eder. $\mathrm{Bu}$ bölge genel olarak ince taneli kötü boylanmalı gevşek kum ve siltlerden oluşmuştur. Tarımsal arazilerin az olması bu bölgede su kalitesini artıran diğer bir etken olabilir. Düşük su kalitesi içeren alanlar ise inceleme alanının kuzeydoğusunda yer alır. Düşük su kalitesi içeren alanlar toplam alanın yaklaşık \% 26.8 temsil eder. Güneye doğru gidildikçe mesafeye bağlı olarak su kalitesi artma eğilimi gösterir. İnceleme alanının \% 45.7'si su kalitesi açısından orta sukalite özelliğine sahiptir. İçme ve kullanma suyunun kalitesi Tuz Gölü'ne yaklaştıkça ve Eskil ovasının güney kesimine doğru inildikçe azalma gösterir.

\section{SONUÇ ve ÖNERILER}

Bu çalışma kapsamında Eskil ve çevresinde yer alan yeraltı suyu kalitesini içme ve kullanma suyu yönünden değerlendirebilmek amacı ile AHP yöntemi kullanılarak bir su kalite indeksi geliştirilmiştir. Su kalite indeksinin oluşturulmasında Mayıs ve Eylül 2015 tarihlerinde 21 su kuyusundan alınan su örneklerine ait analiz sonuçları kullanılmıştır. Su kalite indeksini oluşturan kriterler uzman görüşlerine ve su kalite standartları dikkate alınarak seçilmiş ve her bir kriter için su kalite durumunu gösterir bir skor elde edilmiștir.Bu sayede toplam su kalitesinin uygunluk oranını gösterir bir indeks geliştirilmiştir.İnceleme alanı için su kalite indeksi çok yüksek kalite (\% 12), yüksek kalite (\% 27), orta kalite $(\% 45)$ ve düşük kalite $(\% 26)$ olarak dört grup altında tanımlanmıştır.

$\mathrm{Su}$ kalite indeksi ve jeoistatiksel bir yöntem olan kriging metot kullanılarak inceleme alanının su kalite dağılım haritaları elde edilmiştir. Bu haritalara göre çok yüksek ve yüksek su kalitesine sahip alanlar inceleme alanının güney ve güneybatısında görülmektedir ve yaklaşık $86 \mathrm{~km}^{2}$ lik bir alan kaplar. İnceleme alanında $\mathrm{CaHCO}_{3}$ fasiyes türü baskındır fakat $\mathrm{NaCl}$ ve $\mathrm{CaHCO}_{3}$ fasiyeslerinin farklı oranlarda karışmalarından dolayı bölgede karışım sularını temsil eden $\mathrm{NaHCO}_{3}$ fasiyes türleri gelişmiştir. Sk2, Sk8, Sk10, Sk11, Sk12 ve Sk18 numaralı kuyular nitrat açısından, Sk1, Sk11 ve Sk12 numaralı kuyular $\mathrm{Cl}$ ve $\mathrm{Na}$ iyon içeriği açısından düşük su kalitesine sahiptir. Sk1 ve Sk16 numaralı kuyular As, Sk1, Sk4, Sk11, Sk12, Sk16 ve Sk19 numaral1 kuyular ise B açısından sınır değerleri aşmıştır ve içme suyu olarak kullanılmaları sakıncalıdır. Bütün su kaynakları tarımsal sulama için kullanılabilir.

Göl kıyısına yakın konumda bulunan Sk1, Sk2, Sk4, Sk11 ve Sk12de tatlı su akiferlerinin tuz içeriği artış gösterir. Kuyularda aşırı su çekimine bağlı olarak yeraltı suyu seviyesinde gelişen aşırı düşüm gölü çevreleyen tuzlu bölgeden akifere tuzlu su girmesine neden olmuş olabilir. Kırık sistemler ve gözenekli birimler boyunca etkili olan tuzlu su girişi alüvyon akiferin litolojik özelliklerine göre de farklılıklar gösterecektir.

$\mathrm{Bu}$ çalışma sonucunda önerilen metot yüksek su kalitesine sahip alanların belirlenmesinde ve su kalite değerlendirme çalışmalarında güvenilir ve başarılı bir şekilde kullanılabilir.Bölgede yüksek su kalitesine sahip alanları gösterir su kalite haritalarının kullanımı tarımsal ürünlerin yetiştirilmesinde ürün verimliliğini artıracağ 1 gibi aynı zamanda düşük su kalitesine sahip bölgelerde açılan kuyulardan dolayı oluşabilecek ekonomik zararları da azaltacaktır.Ínceleme alanı için üretilen su kalite haritaları yerel yöneticiler, ziraat mühendisleri, şehir ve bölge plancıları tarafından kullanılabilir.

\section{KAYNAKLAR}

Abtahi, M., Golchinpour, N., Yaghmaeian, K., Rafiee, M., Jahangiri-rad, M., Keyani, A., Saeedi, R. 2015. A modified drinking water quality index (DWQI) for assessing drinking source water quality in rural communities of Khuzestan Province, Iran. Ecological Indicators, 53: 283-291.

Aldworth, J. 1998. Spatial Prediction, Spatial Sampling, and Measurement Error. Ph.D.Thesis, Iowa State University, Iowa, USA, 167p.

Arıkan, Y. 1975. The geology and petroleum prospects of the Tuz Gölü Basin. Bulletin of the Mineral Research and Exploration Institute of Turkey, 85:1744.

Banerjee, T., Srivastava, R. 2009.Application of water quality index for assessment of surface water quality surrounding integrated industrial estate-Pantnagar. Water Sci. Technol. 60(8): 2041-205.

Bardalo, A.A., Nilsumranchit, W., Chalermwat, K. 2001. Water quality and uses of the Bangpakong river (Eastern Thailand). Water Resource, 35: 36353642.

Bolstad, P. 2005. GIS Fundamentals: A First Text on Geographic Information Systems. Eider Press.

Boyacioglu, H. 2007. Development of a water quality index based on a European classification scheme. Water Sa, 33(1):1-6.

Chapra, S.C. 2008. Surface water-quality modeling. Waveland Press.

Cordy, G.E. 2001.A Primer on Water Quality. USGS report no: 027-01. http://pubs.usgs.gov/fs/fs-027-01/. Accessed December 2, 2015.

Clark, I. 1979. Practical Geostatistics. Applied Science Publishers. London, Britain.

Çemen, İ., Göncüoğlu, M.C., Dirik, K. 1999. Structural evolution of the Tuz Gölü Basin in Central Anatolia, Turkey. The J. Geol., 107(6): 693-706.

Diersing, N., Nancy, F. 2009. Water quality: Frequently asked questions. PDA. NOAA. 
Dirik, K., Erol, O. 2000. Tuzgölü ve civarının tektonomorfolojik evrimi, Orta Anadolu, Türkiye. Haymana-Tuzgölü-Ulukışla Basenleri Uygulamalı Çalışma (Workshop), 09-11 Ekim 2000, Türkiye Petrol Jeologları Derneği, Özel Sayı, 5: 27-46.

Fu, P., Sun, J. 2010. Web GIS: principles and applications. Esri Press.

Germolec, D.R., Yang, R.S.H., Ackerman, M.F., Rosenthal, G.J., Boorman, G.A., Blair, P., Luster, M.I. 1989. Toxicology studies of a chemical mixture of 25 groundwater contaminants. Fundam. Appl. Toxicol., 13: 377-387

Göncüoğlu, M.C., Dirik, K., Erler, A., Yalınız, K., Özgül, L., Çemen, İ. 1996. Tuzgölü havzası batı kısmının temel jeolojik sorunları. TPAO Rapor No: 3753 (Yayınlanmamış).

Hem, J.D. 1985. Study and interperation of the chemical characteristics of natural water, USGS Water Supply Paper 2254, U. S. Gov. Print Office, 263 p.

Horton, R.K. 1965. An index number system for rating water quality. J. Water Pollut. Control Fed. 37: 300306

Kavurmacı, M.M. 2013. Şereflikoçhisar havzası yeraltı sularının hidrojeolojik ve hidrokimyasal açıdan incelenmesi ve bölgedeki tuzlusu girişiminin çevresel etkilerinin araştırılması. ASÜ Fen Bil. Ens., Jeoloji ABD, DoktoraTezi, $232 \mathrm{~s}$.

Liou, S., Lo, S., Wang, S. 2004. A generalized water quality index for Taiwan. Environ. Monit. Assess. 96: $35-52$

Marjani, A., Jamali, M. 2014. Role of exchange flow in salt water balance of Urmia Lake. Dynamics of Atmospheres and Oceans, 65:1-16

Miller, W.W., Joung, H.M., Mahannah, C.N., Garrett, J.R. 1986. Identification of water quality differences Nevada through index application. J. Environ. Qual. 15: 265-272

Nasiri, F., Maqsiid, I., Haunf, G., Fuller, N. 2007. Water quality index: a fuzzy river pollution decision support expert system. J. Water Resour. Plan. Manag. 133: 95-105

Oliver, M.A. 1990."Kriging: A method of interpolation for geographical information systems". International Journal of Geographic Information Systems, 4: 313 332.

Ramakrishnaiah, C.R., Sadashivaiah, C., Ranganna, G. 2009. Assessment of water quality index for the groundwater in Tumkur Taluk, Karnataka State, India. Journal of Chemistry, 6(2):523-530
Saaty, T.L. 2005. Theory and Applications of The Analytic Network: Decision Making With Benefits, Opportunities, Costs And Risks. 47p, RWS Publication, USA.

Saaty, T.L. 2008. Decision making with the analytic hierarchy process. Int. J. Services Sciences, 1(1): 8398.

Sadat-Noori, S.M., Ebrahimi, K., Liaghat, A.M. 2014. Groundwater quality assessment using the Water Quality Index and GIS in Saveh-Nobaran aquifer, Iran. Environmental Earth Sciences, 71(9):38273843

Selvam, S., Manimaran, G., Sivasubramanian, P., Balasubramanian, N., Seshunarayana, T. 2014. GISbased Evaluation of Water Quality Index of groundwater resources around Tuticorin coastal city, south India. Environmental earth sciences, 71(6): 2847-2867

Sener, E., Davraz, A. 2013. Assessment of groundwater vulnerability based on a modified DRASTIC Model, GIS and an Analytic Hierarchy Process (AHP) method: the case of Egirdir Lake Basin (Isparta, Turkey). Hydrogeology Journal, 21: 701-714

Sun, W., Xia, C., Xu, M., Guo, J., Sun, G. 2016. Application of modified water quality indices as indicators to assess the spatial and temporal trends of water quality in the Dongjiang River. Ecological Indicators, 66:306-312.

Taylor, J.K. 1987. Quality assurance of chemical measurements. CRC Press.

Tercan, A.E., Saraç, C. 1998. Maden Yataklarının Değerlendirilmesinde Jeoistatistiksel yöntemler. TMMOB Jeoloji Mühendisleri Odası Yayınları, 48, Ankara, Türkiye.

Yazgan, E. Üstün, A.K. 2011. Application of analytic network process: weighting of selection criteria for civil pilots. J. Aeronaut Space Technol, 5(2):1-12.

Zarif, İ.H., Özçep, F., Seyyar, T. 2004.Yalova'daki Alüvyon Zeminlerin Sıvılaşma Tehlike Analizi. 16. Uluslararası Jeofizik Kongresi, 7-10 Aralı, Ankara, Türkiye.

WHO/UNICEF 2012. Estimated with data from WHO/UNICEF Joint Monitoring Programme (JMP) for Water Supply and Sanitation. Progress on Sanitation and Drinking-Water, 2012 Update. 